\title{
ESPAÇOS LIVRES NA ÁREA URBANA DE PARANAGUÁ (PARANÁ, BRASIL)
}

\author{
Emerson Luis Tonetti ${ }^{12}$; João Carlos Nucci ${ }^{3}$; Simone Valaski ${ }^{4}$
}

\section{RESUMO}

A existência de Espaços de Uso Público e Livres de Edificação é um fator de enorme importância para a qualidade ambiental urbana. É muito difícil desenvolver um índice ideal para os espaços livres, sugere-se, portanto, a comparação entre diferentes locais, visando, no mínimo, uma reflexão acerca da questão. Por meio de trabalho de campo, os espaços de uso público e livres de edificações da área urbana do município de Paranaguá, foram identificados e posteriormente mapeados em escala 1:15.000 por meio do software AutoCAD. Os resultados encontrados foram: 1,33\% da área total ocupados por espaços de uso público e livres de edificações e $3 \mathrm{~m}^{2}$ de espaços livres por habitante. Os espaços livres se encontram isolados e mal distribuídos, apresentando várias barreiras de acesso. Os resultados foram comparados com outros locais no Brasil e com algumas cidades alemãs. Concluiu-se que há um déficit de espaços livres na área e que a situação deve piorar devido ao adensamento urbano proposto pelo atual Plano Diretor do município.

Palavras chave: Qualidade Ambiental Urbana; Espaços Livres de Edificação; Planejamento da Paisagem; Ecologia Urbana.

\section{OPEN SPACES IN URBAN AREA OF PARANAGUÁ (PARANÁ, BRAZIL)}

\section{ABSTRACT}

The presence of open spaces is a factor of huge importance for the maintenance and improvement of the urban environmental quality. It is very difficult to develop an ideal index for open spaces, therefore it is suggested the comparison between the different sites, focusing at least, a reflection about the issue. In this work, the open spaces of Paranaguá urban area has been stored based in field visits and information transfered to digital format, using AutoCAD, software that helped the thematic map elaboration in the scale 1:15.000. The found were just 1,33\% and $3 \mathrm{~m}^{2}$ of open spaces per inhabitants. These open spaces appear as isolated, badly distributed places and some streets working as barriers to the acesses. The found were compared with other Brazilian sites, as well as with some German cities. It was concluded that there is a shortage of open spaces in the area and that the situation should get worse due to urban higher density proposed by the current Master Plan of the municipality.

Keywords: Urban environmental quality; Non-built-up spaces; Landscape Planning; Urban Ecology.

\footnotetext{
${ }^{1}$ Graduação e mestrado em Biologia, Universidade Federal do Paraná (UFPR), doutorado em Geografia, Departamento de Geografia da UFPR, professor do Instituto Federal do Paraná (IFPR) campus Paranaguá, Paraná. emerson.tonetti@ifpr.edu.br

2 (recebido em 28.07.2011 e aceito para publicação em 15.06.2012)

${ }^{3}$ Graduação em Biologia (Instituto de Biociências da Universidade de São Paulo), doutorado em Geografia (Departamento de Geografia Faculdade de Filosofia, Letras e Ciências Humanas - Universidade de São Paulo), professor do Departamento de Geografia da Universidade Federal do Paraná, Curitiba, Paraná. nucci@ufpr.br

${ }^{4}$ Graduação, mestrado e doutoranda em Geografia. Departamento de Geografia da Universidade Federal do Paraná, Curitiba, Paraná. simonevalaski@ig.com.br
} 


\section{INTRODUÇÃO}

Os ambientes urbanos crescem ocupando, com edificações e outras construções, áreas que desempenham serviços ecológicos importantes na manutenção e melhoria da saúde do cidadão e da qualidade do ambiente urbanizado, e que poderiam ser destinadas como Espaços de Uso Público e Livres de Edificação (EUPLEs) ${ }^{5}$. Em Paranaguá, município do litoral do Paraná, com importância nacional pela presença do Porto Dom Pedro II e com uma população urbana de 140.450 habitantes (IBGE, 2010), o processo de ocupação não foi diferente e promoveu a expansão horizontal da área urbanizada sobre a planície costeira, ocupando manguezais, restingas e margens de rios. O diagnóstico da quantidade, diversidade, qualidade e da distribuição dos Espaços de Uso Público Livres de Edificações (EUPLEs), com e sem vegetação, é de fundamental importância para a garantia de uma boa qualidade do ambiente urbano. Como um dos critérios para a determinação da Qualidade Ambiental Urbana (TONETTI, 2011), este artigo apresenta um diagnóstico com base na quantidade e na distribuição dos EUPLEs em parte da área urbanizada do Município de Paranaguá.

\section{REFERENCIAL TEÓRICO}

Vários aspectos que ligam a saúde humana com a condição do ambiente local e com a localização da vegetação nas áreas urbanas são abordados por Jackson et al. (2003) quando afirmam que a exposição dos habitantes à luz natural e a ventilação, as oportunidades de observação, contato e a proximidade de espaços com vegetação colaboram na restauração da saúde física e mental. No entanto, variáveis como a quantidade, a qualidade e a distribuição dos espaços livres que possam permitir o maior contato do cidadão com a natureza e possibilidades de socialização e expressão cultural não

\footnotetext{
${ }^{5}$ A expressão Espaços de Uso Público, Livres de Edificação e com Vegetação e a sigla (EUPLEVs) foram elaboradas por Buccheri Filho (2010) em sua tese de doutoramento que se encontra disponível em: http://hdl.handle.net/1884/24093
}

são, frequentemente, consideradas no planejamento urbano (NUCCI et al., 2005). Lima et al. (1994), Nucci e Cavalheiro, (1999) e Nucci (2008) comentam que um ponto muito discutido, quando se fala sobre espaços não edificados com ou sem predomínio da vegetação no meio urbano, é a questão dos termos e dos índices utilizados para demonstrar sua área de cobertura. Existe muita confusão por causa das várias definições e de diferentes métodos utilizados no estudo desses espaços, o que dificulta a identificação, a classificação e a quantificação, sendo a escolha de índices uma tarefa muito difícil. Cavalheiro et al. (1999), no intuito de colaborar com a questão, propuseram definições diferenciadas, mas complementares para dois termos fundamentais: “espaços livres de construção” e “áreas verdes”.

Espaços livres de construção: constituem-se de espaços urbanos ao ar livre, destinados a todo tipo de utilização que se relacione com caminhadas, descanso, passeios, práticas de esportes e, em geral, a recreação $e$ entretenimento em horas de ócio; os locais de passeios devem oferecer segurança e comodidade com separação total da calçada em relação aos veículos; os caminhos devem ser agradáveis, variados e pitorescos; os locais onde as pessoas se locomovem por meios motorizados não devem ser considerados como espaços livres. Os espaços livres podem ser privados, potencialmente coletivos ou públicos e podem desempenhar, principalmente, funções estética, de lazer e ecológicoambiental, entre outras. (CAVALHEIRO, et al., 1999, p. 7)

Áreas verdes são um tipo especial de espaços livres onde o elemento fundamental de composição é a vegetação. Elas devem satisfazer três objetivos principais: ecológico-ambiental, estético e de lazer. Vegetação e solo permeável (sem laje) devem ocupar, pelo menos, $70 \%$ da área; devem servir a população, propiciando um uso e condições para recreação. Canteiros, pequenos jardins de ornamentação, rotatórias e arborização não podem ser considerados áreas verdes, mas sim "verde de acompanhamento viário", que com as calçadas (sem separação total em relação aos veículos) pertencem à categoria de espaços construídos ou espaços de integração urbana (CAVALHEIRO et al., 1999, p. 7.)

Cavalheiro e Del Picchia (1992) consideram os espaços livres como um conceito abrangente onde podem estar inseridas desde parques e praças até águas superficiais e

Emerson Luis Tonetti et al.. 
áreas impermeabilizadas, sendo, portanto, preferível no lugar do termo "área verde".

Lima et al. (1994), também concordam que um conceito mais abrangente e que poderia ser utilizado no ordenamento da paisagem parece ser o de Espaço Livre.

Guzzo (1999), ao utilizar o termo Espaços Livres de Uso Público (ELUP), trouxe um avanço na questão explicando que esses espaços definem áreas cujo acesso das pessoas é livre, fazendo parte do conceito praças, parques, sistemas de lazer e cemitérios.

Guzzo, et al. (2006) utilizaram, no município de Ribeirão Preto/SP, a expressão Espaço Livre Urbano para identificar todos os espaços da cidade em que não há edificações, ou espaços abertos para o céu, englobando as praças públicas, os parques urbanos, as áreas verdes públicas, os cemitérios como espaços públicos e o Campus Universitário como espaço livre urbano potencialmente coletivo com possibilidade de uso público, mas com algumas restrições quanto à acessibilidade da comunidade.

Para Llardent (1982) um Sistema de Espaços Livres poderia ser definido como sendo o conjunto de espaços urbanos ao ar livre, destinados a caminhadas, descanso, passeios, a prática esportiva, recreio e entretenimento nas horas de ócio, sendo todas essas atividades exercidas em contraposição ao movimento motorizado.

À título de exemplo quantitativo e ainda segundo Llardent (1982), um conjunto residencial poderia ter seus espaços divididos em: área construída (37,8\%), sistema viário e estacionamentos (19,6\%) e sistema de espaços livres (42,6\%). O Sistema de Espaços Livres estaria subdividido em: jardim de jogos infantis, área de jogos equipados, área de jogos livres, rede de passeios a pé, zonas de repouso e zonas verdes.

Nucci e Presotto (2009) afirmam que a contraposição entre “área construída” e "espaço livre” pode trazer alguma confusão, mas que pelos exemplos citados por Llardent (1982), pode-se constatar que os espaços livres são livres de edificação e não de construção. Assim, as áreas de jogos, os caminhos, as zonas de repouso, certamente apresentam construções, tais como rede elétrica, de água e de esgoto, bancos, áreas impermeabilizadas para facilitar as caminhadas e os jogos, porém, devem apresentar poucas edificações, talvez sanitários, quiosques, ou seja, uma infra-estrutura mínima para o uso dos espaços. ${ }^{6}$

Nesse ínterim, Belem e Nucci (2010) substituíram o termo “construção" pelo termo “edificação" devido à necessidade de se enfatizar a inexistência de qualquer tipo de estrutura com pelo menos um pavimento evitando assim confusões com o termo “construção , pois este pode ser relacionado à quadras esportivas, estátuas, pequenos monumentos, pontes, entre outros tipos de construções que não acarretam os efeitos que uma edificação com um ou mais pavimentos causaria.

Nucci e Valaski (2009), com base nas contribuições de Cavalheiro e Del Picchia (1992), Cavalheiro et al. (1999), Nucci (2001) e Cavalheiro et al. (2003), sugeriram uma classificação para os espaços urbanos, subdividindo-os em:

- Sistemas de Espaços não Edificados (todos os espaços ao ar livre que não apresentam estruturas como telhados e paredes, nem garagens sob ou sobre a superfície da terra, ou infra-estrutura para realização de obras de construção; os espaços podem ter superfície impermeável e englobam também superfícies com água, tais como rios, lagos, piscinas, etc.);

- Sistema de Espaços Edificados (todos os espaços urbanos com presença de qualquer estrutura com teto e parede, sobre ou sob a superfície da terra) e

- Sistema de Espaços de Integração Viária (todas as ruas de transporte terrestre, incluindo estacionamentos e calçadas que não apresentam separação entre pedestres e veículos motorizados).

Como o espaço livre de edificação pode ainda ser público ou privado, o que implicaria uma verificação da propriedade, ou seja, descobrir a quem pertence a área, se ao poder público ao a particulares e, ainda conter ou não vegetação, Buccheri-Filho (2010) propôs uma expressão ainda mais esclarecedora: "Espaços de Uso Público, Livres de Edificação com Vegetação" (EUPLEVs) ou, sem especificar a presença ou não de vegetação, apenas

\footnotetext{
${ }^{6}$ Ainda sobre os usos dos termos “construção” e "edificação” em se tratando de Espaços Livres, indica-se o trabalho de Cavalheiro, Presotto e Rocha (2003). Em Toledo e Santos (2008) encontra-se uma revisão de conceitos relevantes no que se referem aos espaços livres de construção.
} 
como "Espaços de Uso Público, Livres de Edificação" (EUPLEs). A utilização do termo “uso público" reforça a importância do acesso da população ao espaço, seja ele de propriedade pública ou privada.

Além da questão da terminologia, é preciso levar em consideração as funções dos espaços livres no meio urbano. A relação da quantidade, qualidade e estética dos espaços livres com as edificações é apontada por Sitte (1992) como um princípio básico para o uso do solo urbano.

Sukopp e Werner (1991) afirmam que no meio urbano são necessários mais espaços livres com vegetação, até se conseguir uma rede que cubra a área completa em um gradiente de diferentes intensidades de uso.

Nucci (2008) destaca a importância da qualidade dos espaços livres em relação às questões de tamanho, manutenção, localização em relação ao tráfego e a distância da residência entre outras questões que devem ser consideradas para garantir a função e o valor social destas áreas.

Sukopp e Werner (1991) também afirmam que a importância dos espaços livres urbanos se reduz significativamente pelo alto nível de tensão (ruído, contaminação) e agressões (pisoteio, cortes) a que estão submetidos, especialmente aos situados no centro das cidades, ao longo das rodovias e das zonas industriais emissoras de fumaça.

A disponibilidade dos espaços livres com qualidade e nas proximidades das residências além de desempenharem funções de lazer, mesmo que restrita a determinadas faixas etárias da população podem desempenhar funções ecológicas importantes, mesmo que não contenham a vegetação. Locais como as praças, largos de igrejas, campos de jogos de areia, por exemplo, podem atuar na infiltração da água no solo e podem reter temporariamente a água das chuvas reduzindo o volume de água escoado superficialmente e, consequentemente, reduzir as chances de inundações.

A multifuncionalidade dos espaços urbanos é um ponto importante no trabalho de Hough (1998). Cada um destes locais atenderia a demanda de certos segmentos da população. Os campos de jogos e os playgrounds, por exemplo, atenderiam mais adolescentes e crianças, respectivamente. Daí a importância da diversidade desses espaços para atender todos os segmentos da população, além das questões relacionadas com a qualidade e a distância da residência.

\section{MÉTODO}

O recorte espacial do estudo engloba a parte central da área urbana do Município de Paranaguá, no litoral do Estado do Paraná (FIGURA 1).

A área total do município é de 826,65 km², a área urbana é de $95,15 \mathrm{~km}^{2}$ e o local de estudo possui $11,64 \mathrm{~km}^{2}$. O marco zero do município encontra-se nas coordenadas $25^{\circ} 18^{\prime} 00^{\prime \prime} \mathrm{S}$ e $48^{\circ} 21^{\prime} 00^{\prime}$ ' W. Limita-se ao norte com a Baía de Paranaguá e o município de Guaraqueçaba (PR), ao sul com os municípios de Guaratuba (PR) e Matinhos (PR), à leste com o município de Pontal do Paraná (PR) e a oeste com os municípios de Antonina (PR) e Morretes (PR).

A ocupação de Paranaguá se deu por volta de 1550, na Ilha de Cotinga, ligada ao início da exploração do ouro no Brasil e a ocupação do continente ocorreu cerca de 20 anos mais tarde. Em 1648 o povoado foi elevado oficialmente à condição de vila. Este núcleo urbano estruturava-se nas imediações da atual Igreja Matriz e da Fonte Velha. Os jesuítas chegaram em 1699 e em 1740 começou a construção do colégio, atual Museu de Arqueologia e Antropologia da Universidade Federal do Paraná. Nesse período o novo cais de pedra foi construído em frente à Casa de Câmara e Cadeia, na margem do Rio Itiberê, como o anterior, estimulando a expansão urbana para o local, dando início à estruturação da atual Rua General Carneiro, com seu casario. Do final do século XVIII até 1896 a estrutura da cidade permaneceu praticamente a mesma. A expansão das atividades Emerson Luis Tonetti et al.. 
portuárias conduziu à construção do Porto Dom Pedro II, na margem da Baía de Paranaguá, em 1935. Novas áreas foram urbanizadas, mas sem o deslocamento do comércio. O centro tradicional persiste e ainda hoje polariza tanto as funções econômicas da cidade quanto de toda a região (IPHAN, 2009; SANTOS, 1952; TRAMUJAS, 1996). Com o aumento da exportação de café, principalmente na década de 1950, ocorreu a ocupação mais intensa e Paranaguá tornou-se pólo de atração de populações do campo e de outras localidades, resultando em desequilíbrios sociais e espaciais no município. Com a crise do café no final da década de 1960, o desemprego aumentou. (CANEPARO, 2000; GODOY, 1998, p. 233-234; TRAMUJAS, 1996).

A partir de 1970 a produção de soja e de trigo, estimuladas pelo governo federal, comandou 0 crescimento agrícola do Paraná. Novos armazéns foram construídos nas imediações do porto, que foi ampliado e remodelado. A manipulação das cargas, realizada por máquinas, passou a substituir a mão-de-obra, gerando redução no nível de emprego, aumentando os problemas sociais na cidade, refletindo-se em uma desorganização do espaço, intensificando a ocupação de áreas de preservação permanente, ou seja, os manguezais e as margens dos rios. (CANEPARO, 2000; GODOY, 1998, p. 233-234; TRAMUJAS, 1996). Este processo se repete nas décadas seguintes com a política de privatização e com a modernização dos equipamentos e instalações portuárias (CANEPARO, 2000; GODOY, 1998, p. 233234; TRAMUJAS, 1996).

Figura 1. Localização da área de estudo em paranaguá (paraná, brasil)

Figure 1. Localization of study area in paranaguá (paraná, brazil)

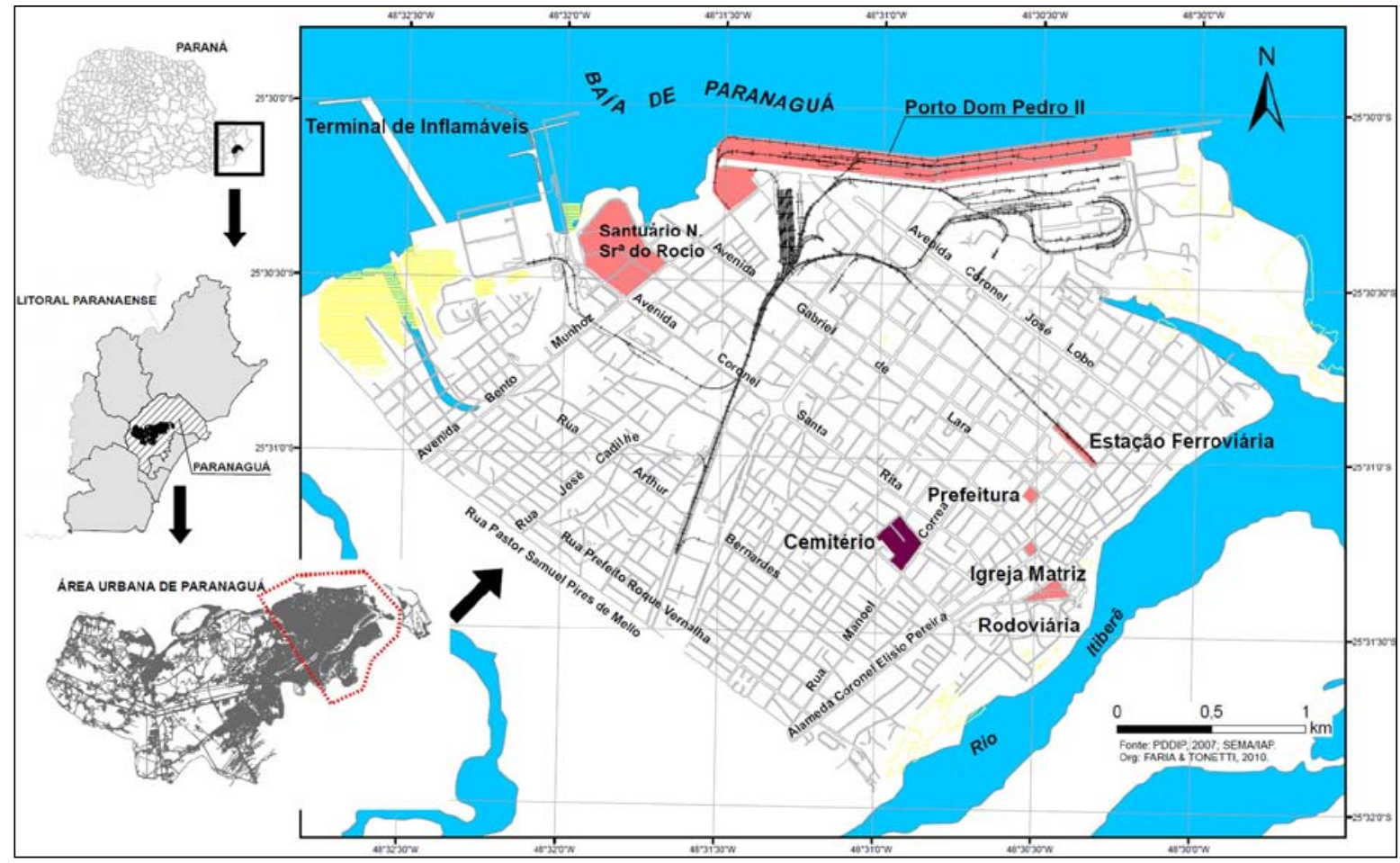

Neste estudo, não houve distinção da presença ou não de vegetação nos espaços livres, por esse motivo utilizou-se somente o termo Espaços de Uso Público Livres de Edificação (EUPLE). Durante o trabalho de gabinete, optou-se por delimitar a capacidade de suporte de cada
EUPLE por meio do cálculo da área de abrangência do espaço livre.

Jenks et al. (1996) e Nucci (2008) comentam que a distância (horizontal e vertical) influencia a frequência do uso de serviços, facilidades ou de equipamentos, ou seja, 
quanto maior a distância ou quanto maior o número de andares dos edifícios menor é a frequência do uso.

Di Fidio (1985) também coloca que em exercendo sua função recreativa, um dos maiores requisitos do espaço livre seria sua localização em relação aos usuários, afirmando que distâncias com a necessidade de mais do que 10 a 15 minutos para serem percorridas a pé, a utilização decai.

Lorusso (1992) orienta para uma melhor distribuição e maior ampliação do “Sistema de Áreas Verdes”, de modo que o usufrutuário não tenha que gastar, andando normalmente, mais do que 10 (dez) minutos para alcançar o equipamento mais próximo.

Barton e Tsourou (2000) ensinam que a acessibilidade é bem diferente em diversos países, mas que um critério deveria ser adotado. Os autores informam que em Bruxelas (Bélgica), Copenhagen (Dinamarca) e Glasgow (Escócia) existe a sugestão de que todos os residentes possam alcançar um espaço livre em até 15 minutos de caminhada.

Sendo assim, um parâmetro considerado equivalente com as propostas acima e adotado para demarcar a área da população assistida pelos espaços livres foi a distância de 300m, o que corresponde a no máximo 4 quadras que separariam a residência do espaço livre.

Outro critério adotado foi a utilização das vias de tráfego intenso e desprovidas de semáforos, como barreiras para a utilização do espaço livre. Dessa forma, os espaços livres que se encontram em uma das margens de certa avenida podem não atender as residências da margem oposta, porque em quase toda sua extensão a via pode apresentar grande intensidade de tráfego de veículos, não possuir semáforos para pedestres. Assim, as vias com tráfego intenso de veículos e desprovidas de semáforos e/ou sinalização, também foram utilizadas como parâmetros para restringir a área de abrangência dos espaços livres no local de estudo.

Em se tratando da porcentagem de área ocupada por espaços livres, à título de comparação, optou-se pelos valores sugeridos pelos setores de planejamento urbano na Alemanha, ou seja, 40\% para espaços construídos, $20 \%$ para o sistema viário e $40 \%$ para espaços livres de construção (NUCCI, 2008), além dos dados encontrados em Berlim (2001) sobre algumas cidades alemãs, como também outros dados encontrados em Llardent (1982), bem como em outros estudos realizados em cidades brasileiras.

Toda a área foi percorrida a pé, nos meses de julho e agosto de 2008, tendo em mãos uma carta cadastral na escala 1:5.000, obtida no setor de urbanismo da Prefeitura Municipal de Paranaguá, onde foi possível a identificação de cada lote e a localização dos espaços de uso público livres de edificações.

Por meio do software AutoCAD, os dados coletados em campo foram lançados na carta base, georeferenciada, na escala 1:15.000, da área urbana do município, para obtenção do mapa da distribuição dos espaços de uso público e livres de edificações e suas respectivas áreas de influência. A área de cada espaço livre foi obtida pela seleção dos polígonos no software e posteriormente utilizada na composição das informações da tabela de espaços livres desse segmento urbano.

\section{RESULTADOS E DISCUSSÃO}

A soma das áreas de todos os 41 Espaços de Uso Público, Livres de Edificação (EUPLEs) identificados no levantamento de campo perfaz $155.823,1 \mathrm{~m}^{2}$, o que corresponde a 1,33\% da área total que é de 11.644.379,85 $\mathrm{m}^{2}$, valor muito inferior aos recomendados pelos setores de planejamento da Alemanha, os sugeridos por LLardent (1982) e os encontrados em algumas das principais cidades da Alemanha (TABELA 1), ou seja, 40\%. 
Tabela 1. Usos da terra em diferentes cidades da Alemanha

Table 1. Land use in different German cities

\begin{tabular}{|c|c|c|c|c|c|c|c|}
\hline \multirow[b]{2}{*}{ Usos da terra } & \multicolumn{5}{|c|}{ Espaços Livres de Edificação } & \multicolumn{2}{|c|}{$\begin{array}{c}\text { Espaços Edificados + } \\
\text { Espaços Viários }\end{array}$} \\
\hline & Variado & Água & Floresta & $\begin{array}{l}\text { Agricul- } \\
\text { tura }\end{array}$ & $\begin{array}{l}\text { Parque e } \\
\text { cemitério }\end{array}$ & $\begin{array}{c}\text { Ruas e outras } \\
\text { vias de tráfego }\end{array}$ & $\begin{array}{c}\text { Áreas } \\
\text { edificadas }\end{array}$ \\
\hline "Berlim & $3 \%$ & $6 \%$ & $18 \%$ & $7 \%$ & $11 \%$ & $12 \%$ & $43 \%$ \\
\hline Hamburgo & $8 \%$ & $8 \%$ & $4 \%$ & $30 \%$ & $4 \%$ & $12 \%$ & $34 \%$ \\
\hline Munique & $7 \%$ & $1 \%$ & $5 \%$ & $18 \%$ & $12 \%$ & $17 \%$ & $40 \%$ \\
\hline Colônia & $2 \%$ & $5 \%$ & $14 \%$ & $22 \%$ & $10 \%$ & $15 \%$ & $32 \%$ \\
\hline Frankfurt & 0 & $2 \%$ & $15 \%$ & $28 \%$ & $15 \%$ & $14 \%$ & $25 \%$ \\
\hline Hanover & $6 \%$ & $3 \%$ & $11 \%$ & $19 \%$ & $14 \%$ & $15 \%$ & $33 \%$ \\
\hline Média & $4 \%$ & $4 \%$ & $11 \%$ & $21 \%$ & $11 \%$ & $14 \%$ & $35 \%$ \\
\hline Média & \multicolumn{5}{|c|}{$51 \%$} & \multicolumn{2}{|c|}{$49 \%$} \\
\hline
\end{tabular}

FONTE: BERLIM (2001) e NUCCI E VALASKI (2009). Tradução: João Carlos Nucci, 2011.

Se comparado a alguns dados relacionados por Nucci e Valaski (2009) o valor de 1,33\% só pode ser equiparado ao encontrado por Nucci (1996) para o Distrito de Santa Cecília, que pertence à área central do município de São Paulo (SP), conforme tabela 2.

Em se tratando de Espaços livres urbanos públicos e potencialmente coletivos, Guzzo, et al. (2006) obtiveram o valor de 11,5\% para a área urbanizada do município de Ribeirão Preto (SP) e, considerando os espaços livres essencialmente públicos, ou seja, aqueles sem restrições de acesso à população, bem como a condição de implantado ou urbanizado, o índice de 4,4 $\mathrm{m}^{2} / \mathrm{hab}$. Barbin et al., (2008), utilizando método aplicado por Guzzo (1999) e Guzzo, et al. (2006), encontraram o valor de $4,71 \mathrm{~m}^{2} /$ hab para o Índice de Espaços Livres de Uso Público (IELUP) em um bairro de Piracicaba (SP).

Na área de estudo em Paranaguá, com base nos setores censitários (IBGE, 2000), existem 50.628 habitantes. Dividindo-se o número de habitantes pela área de espaços livres chega-se ao valor de $3 \mathrm{~m}^{2}$ de espaços livres por habitante, portanto inferior aos $5 \mathrm{~m}^{2} / \mathrm{hab}$, como sendo a proposição de valor mínimo encontrado por Nucci (2001) em revisão da literatura. Para atingir os $5 \mathrm{~m}^{2} / \mathrm{hab}$ seriam necessários mais $97.317 \mathrm{~m}^{2}$ de espaços livre no local.

A título de exemplo e de comparação, Llardent (1982) sugere $50 \mathrm{~m}^{2} /$ hab para o Sistema de Espaços Livres, sendo $35 \mathrm{~m}^{2} /$ hab totalmente públicos e livres de regras rígidas. Jámbor e Szilágyi (1984) sugerem para cidades com mais de 10.000 habitantes um total de 21 a $30 \mathrm{~m}^{2}$ de espaços livres públicos por habitante.

$\mathrm{O}$ valor de $3 \mathrm{~m}^{2}$ de espaços livres por habitante torna-se ainda mais contundente se for considerado que a densidade demográfica da área de estudo, de apenas 41,5 habitantes por hectare, certamente será aumentada devido às diretrizes do atual Plano Diretor (PARANAGUÁ, 2007). Com isso, a área de espaços livres disponível para cada habitante, no futuro próximo, será ainda menor.

O aumento da densidade demográfica, prevista por meio da construção de novos edifícios de moradia ou de serviços, deveria estar atrelado, não somente, mas inclusive, ao aumento da área de EUPLEs. Deve-se ainda considerar que os espaços livres, os usos e a população não estão homogeneamente distribuídos. 
Tabela 2. Comparação das proporções nos sistemas de espaços livres de edificação, edificados e de integração viária de algumas localidades

Table 2. Comparison of the proportion between the non-built-up spaces and the built-up system, added to road integration space systems of some sites

\begin{tabular}{|l||c|c||}
\hline \hline Locais & Espaços Livres de Edificação & $\begin{array}{c}\text { Espaços Edificados + } \\
\text { Espaços Viários }\end{array}$ \\
\hline \hline ALEMANHA (1) & $40-50 \%$ & $50-60 \%$ \\
\hline \hline ALEMANHA (2) & $51 \%$ & $49 \%$ \\
\hline \hline SANTA CECÍLIA (3) & $2 \%$ & $98 \%$ \\
\hline \hline ALTO DA XV (4) & $18 \%$ & $82 \%$ \\
\hline \hline BACACHERI (5) & $30 \%$ & $70 \%$ \\
\hline \hline BOQUEIRÃO (6) & $21 \%$ & $79 \%$ \\
\hline \hline SANTA FELICIDADE (7) & $44 \%$ & $53 \%$ \\
\hline \hline CENTRO (8) & $7 \%$ & $93 \%$ \\
\hline
\end{tabular}

(1) Proposição para cidades na Alemanha (Cavalheiro e Del Picchia, 1992). (2) Média para algumas cidades, conforme tabela 1 neste artigo. (3) Distrito do município de São Paulo/Brasil (Nucci, 2001). (4) Bairro de Curitiba/Pr/Brasil - (Buccheri Filho e Nucci, 2006). (5) Bairro de Curitiba/Pr/Brasil - (Pivetta et al., 2005). (6) Bairro de Curitiba/Pr/Brasil - (Valaski e Nucci, 2006). (7) Bairro de Curitiba/Pr/Brasil - (Pivetta, 2006). (8) Bairro de Curitiba/Pr/Brasil - (Nucci e Valaski, 2009).

A figura 2 mostra que há um maior número de espaços livres na parte leste da cidade, principalmente, no centro histórico e no seu entorno, onde há grande concentração de usos comerciais e menor número de residências. Desta maneira os espaços livres dessa área acabam exercendo mais uma função estética e de lazer apenas para os visitantes da cidade. Na porção oeste a situação se inverte, pois há mais uso residencial e menor oferta de espaços livres.

Além da distribuição dos Espaços Livres, na figura 2 também pode ser observado a área ocupada pela população assistida pelo conjunto de espaços livres com base na distância de 300m e no isolamento em relação ao tráfego de veículos.

Os nomes e a área correspondente a cada um desses espaços livres são apresentados na tabela 3.

Percebe-se que a área de abrangência de alguns EUPLEs poderia ser maior, porém, muitas das vias com tráfego intenso de veículos leves e/ou pesados e desprovidas de semáforos atuam como barreiras ao deslocamento de ciclistas e pedestres e, consequentemente, dificultam sua utilização. É o caso dos espaços livres nas movimentadas avenidas Airton Senna da Silva e Prefeito Roque Vernalha, que não atendem as residências do outro lado porque possuem apenas um ou dois semáforos e não possuem sinalização nem temporizador para o pedestre.

A utilização de semáforos e da sinalização adequada poderia facilitar o deslocamento das pessoas e melhorar o acesso aos EUPLEs e melhorar as condições para a mobilidade ativa nos locais em que isso é possível, ou seja, em locais onde existem ciclovias e calçadas em bom estado de conservação.

Nas proximidades do centro histórico e comercial a maioria dos espaços livres permite o lazer passivo principalmente para a apreciação visual. São pequenas praças com bancos para contemplar o Rio Itiberê, por exemplo. O restante dos espaços livres possibilita o lazer ativo e são principalmente quadras de futebol ou de voleibol de areia, que atendem determinados segmentos da população. 
Figura 2. Espaços de uso público e livres de edificações e áreas de influência (Paranaguá, PR) Figure 2. Open spaces and influence area (Paranaguá, PR).

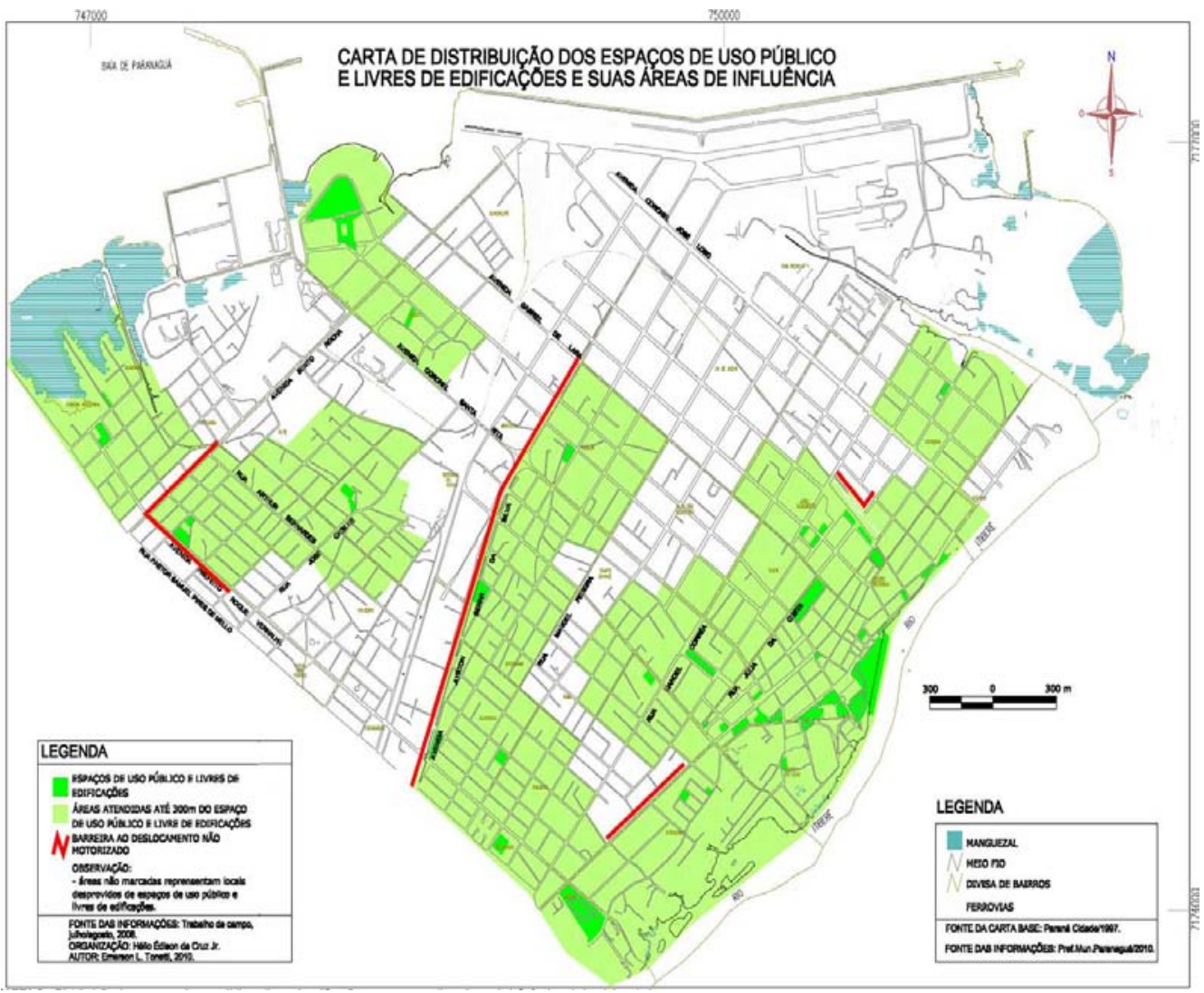

Não se considerou a qualidade de cada EUPLEs e nem a potencialidade para as funções ecológicas e de lazer de cada espaço livre. No entanto, durante as atividades de campo percebeu-se que existem diferenças entre eles em relação a função ecológica que desempenha, a qualidade dos equipamentos e aos segmentos populacionais a que atendem. Por exemplo, em toda área de estudo, ou seja, nos 41 espaços livres identificados, foi encontrado apenas um playground. Trabalhos futuros poderiam avaliar a qualidade e a potencialidade das funções estética, ecológica e de lazer destes espaços livres. Se possível, verificar a viabilidade do uso para as questões de segurança, das barreiras de acesso, de localização em relação as fontes poluidoras e a que faixas etárias da população estes equipamentos urbanos se destinam. Apesar da condição precária encontrada em se tratando dos espaços livres, Paranaguá disponibiliza para a população um parque no entorno do aeroporto municipal, o chamado aeroparque, mas que se encontra fora da área deste estudo, a 3,5km do Centro Histórico. O aeroparque dispõe de equipamentos para musculação, bancos, pista para correr ou caminhar, quadra para futebol de areia, pista para motocross, entre outros, sendo um espaço de grande importância para a população, mas que centraliza o lazer em apenas uma área do município; outros espaços com funções semelhantes deveriam ser distribuídos pelo município, constituindo um sistema de espaços livres para atender a toda população.

As áreas ocupadas preferencialmente pelo uso residencial possuem poucos espaços livres, porém diversos terrenos baldios (TONETTI, 2011), que poderiam ser desapropriados e convertidos em espaços livres pela prefeitura mediante a necessidade ou liberados para o uso público sem necessidade de desapropriação. Essas providências ajudariam a resolver a necessidade de implantação de novas áreas com EUPLEs no município. 
Tabela 3. Espaços de uso público e livres de edificações encontrados na área de estudo (Paranaguá, PR) Table 3. Open spaces in study area (Paranaguá, PR)

\begin{tabular}{|c|c|c|}
\hline NOME & ÁREA m ${ }^{2}$ & LOCALIZAÇÃO \\
\hline Praça Tupi & $3.056,34$ & Rua Tupinambá esquina com Rua Tapajós \\
\hline Praça da Fé & $22.608,27$ & Rua Felipe Mattar esquina com Avenida Coronel Santa Rita \\
\hline Praça Tomas Cheehan & $8.857,72$ & Entre ruas Felipe Mattar, Prof. Décio, Xavier da Silva e Pç da Fé. \\
\hline Praça Irmã Maria Letícia & 863,11 & R. Desemb. Ermelino de Leão esquina com Theodorico dos Santos \\
\hline Praça Reinaldo Elias & $3.337,06$ & Rua Tapajós esquina com Rua Fr. José Tomaz \\
\hline Praça Reinaldo Elias & 953,51 & Rua Fr. José Tomaz esquina com Rua Ildefonso Munhoz da Rocha \\
\hline Pç. Rosa Maria Alboit Ramos & $2.885,60$ & Entre ruas Br. do Amazonas, Pres. Getúlio Vargas e José Cadilhe \\
\hline Praça Claudio Dias & $2.219,78$ & Rua Soares Gomes esquina com Rua Xavier da Silva \\
\hline Praça da Bíblia & 797,11 & Entre as ruas João Eugênio, Arthur de Abreu e Salim Jorge Chede \\
\hline Praça da Bíblia & 910,12 & Entre as ruas João Eugênio, Arthur de Abreu e Salim Jorge Chede \\
\hline Praça João Guarberto & 934,19 & Entre as ruas João Eugênio e Salim Jorge Chede \\
\hline Praça da Marinha do Brasil & $1.076,36$ & Rua Arthur de Abreu esquina com a Rua João Eugênio \\
\hline Pç. Pastor Ademar Frezzatti & 876,96 & Rua Arthur de Abreu esquina com a Rua Julia da Costa \\
\hline Praça Fernando Amaro & $2.919,35$ & Rua Preciliano Corrêa esquina com a Rua Faria Sobrinho \\
\hline Praça Manoel Ricardo & $1.066,68$ & Rua XV de Novembro esquina com a Rua Preciliano Corrêa \\
\hline Praça Rosa Antônio Andrade & 964,90 & Rua XV de Novembro esquina com a Rua Princesa Izabel \\
\hline Pç. Dr. Belmiro S. da Rocha & $1.596,22$ & Rua Ildefonso Munhoz da Rocha esquina com Rua Cons. Corrêa \\
\hline Praça Duque de Caxias & $1.770,09$ & Rua Maneco Viana esquina com Rua Odilon Mader \\
\hline Pç. Leocádio J. Corrêa (da Paz) & $4.036,92$ & Rua Padre Albino esquina com Rua José Gomes \\
\hline Praça Eufrásio Corrêa & $9.973,31$ & Rua Gabriel de Lara esquina com Rua Julia da Costa \\
\hline Pç. Newton D. de Souza & 619,50 & Rua Preciliano Corrêa esquina com a Rua General Carneiro \\
\hline Pç. do conj. Visc. do Rio Branco & $1.285,97$ & Entre as Ruas Setenta e Um e Sessenta e Seis \\
\hline Pç Andréia de Souza Oliveira & 463,44 & Rua Domingos Peneda esquina com a Travessa Omar Pereira \\
\hline Praça Ouvidor Pires Pardinho & 286,99 & Rua Julia da Costa esquina com a Rua dos Expedicionários \\
\hline Praça Acrísio Guimarães & 728,22 & Rua Vieira dos Santos esquina com a Rua Padre Albino \\
\hline Praça da República & 535,36 & Rua Cons. Sinimbu esquina com Rua Joaquim Ferreira Barbosa \\
\hline Praça Fonte Velha & $2.033,05$ & Rua João Estevão atrás do prédio da Copel (Fontinha) \\
\hline Praça do Japão & $1.354,03$ & Entre as Ruas João Estevão, Pecêgo Junior e Constantino \\
\hline Praça de Portugal & $19.617,10$ & Rua Pref. Roque Vernalha esquina com a Al. Cel. Elysio Pereira \\
\hline Pç. do Estádio de Futebol & $1.431,60$ & Rua da Praia esquina com Rua L. \\
\hline Praça na frente da Matriz & 430,24 & Entre as ruas Professor Cleto, Pecêgo Junior e João Régis \\
\hline Praça da Rodoviária & $9.668,90$ & Entre as Ruas João Estevão, Rua da Praia e João Régis \\
\hline Praça 29 de Julho & $33.524,85$ & Rua da Praia \\
\hline Praça do Pelourinho & 973,55 & Rua General Carneiro esquina com a Rua Fernando Simas \\
\hline Área aberta de uso comum* & $1.546,38$ & Entre ruas Xavier da Silva, Estrada Velha do Rocio e Fr. José Thomaz \\
\hline Pequena área com banco* & 829,23 & Rua Ildefonso Munhoz da Rocha esquina com Rua Tamoio \\
\hline Campo de futebol de areia* & $1.049,50$ & Rua Constantino esquina com a Rua L \\
\hline Campo de futebol de areia* & $2.146,68$ & Rua João Estevão ao lado da Copel \\
\hline Campo de futebol de areia* & $4.097,09$ & Rua Soares Gomes esquina com Rua Presidente Getúlio Vargas \\
\hline Campo de futebol de areia* & $1.319,05$ & Rua dos Expedicionários ao lado do Cemitério Municipal \\
\hline Campo de futebol de areia* & $3.064,40$ & Entre P. Roque Vernalha, Baroneza do S. Azul e Samuel P. de Mello. \\
\hline TOTAL (41 EUPLEs) & \multicolumn{2}{|c|}{$155.823,1 \mathrm{~m}^{2}$} \\
\hline
\end{tabular}

FONTE: PREFEITURA MUNICIPAL DE PARANAGUÁ e trabalho de campo (2008). 


\section{CONCLUSÕES}

Foram identificados 41 Espaços de Uso Público, Livres de Edificação (EUPLEs), que somam $155.823,1 \mathrm{~m}^{2}$, valor que corresponde a $1,33 \%$ da área total e um índice de $3 \mathrm{~m}^{2}$ de espaços livres por habitante.

Esses valores estão muito abaixo dos sugeridos na literatura estrangeira revisada pelos autores, que se encontram próximos a 40\% para Espaços Livres e por volta de $30 \mathrm{~m}^{2} /$ hab para espaços totalmente públicos e livres de regras rígidas.

Além disso, os resultados encontrados são os mais baixos em relação aos estudos até agora realizados seguindo o mesmo método em localidades brasileiras.

Pode-se concluir que no segmento urbano estudado de Paranaguá há uma grande deficiência de espaços de uso público e livres de edificações para atender a demanda por lazer dos habitantes, não apenas pela área reduzida de espaços livres, mas também pela distribuição desigual e presença de barreiras de acesso.

A distribuição equitativa, com qualidade e acesso seguro aos Espaços de Uso Público Livres de Edificações (EUPLEs) é uma necessidade básica para o lazer que constitui um componente importante da qualidade do ambiente urbano.

Sem a solução dos problemas identificados, torna-se inviável um adensamento populacional, sem o prejuízo da qualidade ambiental urbana, como propõe o atual Plano Diretor do Município de Paranaguá.

\section{REFERÊNCIAS}

BARBIN, H.S.; VELASCO, G.D.N.; ÁLVAREZ, I.A.; LIMA, A.M.L.P. Estudo dos Espaços Livres do bairro Santa Cecília, em Piracicaba, SP. Rev. SBAU, Piracicaba, v.3, n.3, set. 2008, p. 17-35.

BARTON, H.; TSOUROU, C. Health urban planning. A WHO guide to planning for people. Londres: Spon Press (em nome da Organização Mundial da Saúde - WHO), 2000, 184p.

BELEM, A. L. G.; NUCCI, J. C. Espaços urbanos no bairro de Santa Felicidade, Curitiba/PR: conceito, classificação, quantificação e distribuição. Geografia Ensino \& Pesquisa, v. 12, p. 972-985, 2008.

BELEM, A. L. G.; NUCCI, J. C. Classificação dos Espaços Livres de Edificação de acordo com o tipo de uso no bairro de Santa Felicidade (Curitiba - PR). In: João Carlos Nucci (Org.) Planejamento da Paisagem como subsídio para a participação popular no desenvolvimento urbano. Estudo aplicado ao bairro de Santa Felicidade - Curitiba/PR. (e-book) Curitiba: LABS/DGEOG/UFPR, 2010, 277p. Disponível em: <www.geografia.ufpr.br/laboratorios/labs>. Acesso em: 10 mai. 2011.

BERLIM. Berlin Digital Environmental Atlas. 2001. Disponível em http://www.stadtentwicklung.berlin.de/umwelt/umweltatlas/edua index.shtml. Acesso em: 20 mai. 2002.

BUCCHERI FILHO, A. T. Qualidade ambiental no Bairro Alto da XV, Curitiba/PR. 80 f. Dissertação (Mestrado) - Setor de Ciências da Terra, Universidade Federal do Paraná, Curitiba. 2006. Disponível em: <www.geografia.ufpr.br/laboratorios/labs/?pg=publicacoes-php>. Acesso em: 10 ago. 2008.

BUCCHERI FILHO, A. T. e NUCCI, J.C. Espaços livres, áreas verdes e cobertura vegetal no bairro Alto da XV, Curitiba/PR. Revista do Departamento de Geografia/USP, 18 (48-59), 2006. Disponível em: <http://www.geografia.fflch.usp.br/publicacoes/RDG/RDG_18/RDG18_048_\%20059.pdf>. 
BUCCHERI FILHO, A. T. O planejamento dos espaços de uso público, livres de edificação e com vegetação (EUPLEVs) no município de Curitiba, PR: planejamento sistemático ou planejamento baseado em um modelo oportunista? 226p. Tese (Doutorado) - Setor de Ciências da Terra, Universidade Federal do Paraná, Curitiba. 2010. Disponível em:

http://dspace.c3sl.ufpr.br/dspace/bitstream/1884/24093/1/TESE\%20Alexandre\%20Theobaldo\%20Buccheri\%20Filho.pdf Acesso em: 20 out. 2010.

CANEPARO, S. C. Análise da dinâmica espacial da ocupação antrópica em Paranaguá/Pr (1952-1996), através do uso de sistema de informações geográficas. RA'EGA, Curitiba, n. 4, p. 111-130. 2000.

CAVALHEIRO, F.; DEL PICCHIA, P.C.D. Áreas verdes: conceitos, objetivos e diretrizes para o planejamento. In: $1^{\circ}$ CONGRESSO BRASILEIRO SOBRE ARBORIZAÇÃO URBANA/4 ${ }^{\circ}$ ENCONTRO NACIONAL SOBRE ARBORIZAÇÃO URBANA, 4, 1992, Vitória. Anais I e II.1992. p. 29-35.

CAVALHEIRO, F.; NUCCI, J. C.; GUZZO, P.; ROCHA, Y. T. Proposição de terminologia para o verde urbano. Boletim Informativo da Sociedade Brasileira de Arborização Urbana, Rio de Janeiro, v. 7, n. 3, p. 7-7, 1999.

CAVALHEIRO, F.; PRESOTTO, A.; ROCHA, Y.T. Planejamento e projeto paisagístico e a identificação de unidades de paisagem: o caso da Lagoa Seca do bairro Jardim América, Rio Claro (SP). GEOUSP 13, Departamento de Geografia USP, 2003.

Dl FIDIO, M. Architettura del paesaggio-criteri di pianificazione e construzione con numerosi schemi e illustrazioni. Milano: Pirola editore, 1985, 302p.

GODOY, A. M. G. Os impactos socioambientais na expansão do porto de Paranaguá frente à maior inserção do Brasil no mercado internacional. In: Meio ambiente e desenvolvimento no litoral do Paraná: diagnóstico. Curitiba: UFPR, 1998. p. 231-235.

GUZZO, P. Estudo dos Espaços livres de uso público da cidade de Ribeirão Preto/SP, com detalhamento da cobertura vegetal e áreas verdes públicas de dois setores urbanos. Rio Claro - SP., 1999. 125p. (Dissertação de mestrado. Instituto de Geociências e Ciências Exatas da UNESP/Campus Rio Claro)

GUZZO, P.; CARNEIRO, R. M. A.; OLIVEIRA JÚNIOR, H. Cadastro municipal de espaços livres urbanos de Ribeirão Preto (SP): acesso public, indices e base para novos instrumentos e mecanismos de gestão. Rev. SBAU, Piracicaba, v.1, n.1, 2006, p. 19-30.

HOUGH, M. Naturaleza y ciudad: planificacion urbana y processos ecologicos. Barcelona: G. Gilli, 1998. 315 p.

IBGE. Instituto Brasileiro de Geografia e Estatística. Censo Demográfico de 2000. Dados dos Setores Censitários. Disponível em <http://www.ibge.gov.br/home/geociencias/default_prod.shtm\#TOPO>. Acesso em: 12 jul. 2010.

IPARDES. Instituto Paranaense de Desenvolvimento Econômico e Social. Caderno Estatítico do Município de ParanaguáPR. 2010, 29p. Disponível em: <www.ipardes.gov.br/cadernos/Montapdf.php?Municipio> Acesso em: 18 set. 2010.

IPARDES. Instituto Paranaense de Desenvolvimento Econômico e Social. Caderno Estatítico do Município de ParanaguáPR. 2010, 29p. Disponível em: <www.ipardes.gov.br/cadernos/Montapdf.php?Municipio>. Acesso em: 18 set. 2010.

IPHAN - Instituto do Patrimônio Histórico e Artístico Nacional. Centro histórico de Paranaguá é tombado. Disponível em: $\quad$ http://portal.iphan.gov.br/portal/montarDetalheConteudo.do?id=14875\&sigla=Noticia\&retorno=detalheNoticia> . Acesso em: 22 fev. 2010.

JÁMBOR, I. e SZILÁGYI, K. Grünplanung im Rahmen der Stadtentwicklung. Garten + Landschaft, n. 7, p. 30-35.

JACKSON, L.E. The relationship of urban design to human health and condition. Landscape and Urban Planning, v. 64, p. 191-200, 2003.

JENKS, M.; BURTON, E. e WILLIAMS, K. The Compact City: A Sustainable Urban Form? London: E \& FN SPON, 1996. 350p.

LLARDENT, L.R.A. Zonas verdes y espadas libres en Ia ciudad. Madrid: Inst. de Estúdios de Administración Local, 1982, 538p.

LIMA, A. M. L. P.; CAVAlHeIRO, F.; NUCCI, J. C.; SOUSA, M. A. L. B.; FIALHO, N. O.; PICCHIA, P. C. D. Problemas de utilização de termos como espaços livres, áreas verdes e correlatos. In: II Congresso Brasileiro de Arborização Urbana, 1994, São Luis. Anais... São Luis, 1994. v. 1. p. 539-553. 
LORUSSO, D.C.S. Gestão de áreas verdes urbanas. $1^{\circ}$ CONGRESSO BRASILEIRO SOBRE ARBORIZAÇÃO URBANA. $4^{\circ}$ ENCONTRO NACIONAL SOBRE ARBORIZAÇÃO URBANA. Anais ... Vitória, SBAU (Sociedade Brasileira de Arborização Urbana), 1992.

MOURA, A. R. Qualidade ambiental urbana no bairro de Santa Cecília (centro de São Paulo/SP): estudo comparativo e de monitoramento dos anos de 1992 e 2008. 213f. Dissertação (Mestrado) - Setor de Ciências da Terra, Universidade Federal do Paraná, Curitiba. 2010. Disponível em: <http://hdl.handle.net/1884/25053> Acesso em: 12 abr. 2011.

NUCCI, J. C. Qualidade Ambiental e Adensamento Urbano: um estudo de ecologia e planejamento da paisagem aplicado ao distrito de Santa Cecília (MSP). Curitiba: Ed. do autor, 2008 (2ª ed.). 142p. Disponível em: <www.geografia.ufpr.br/laboratorios/labs/?pg=publicacoes-php>. Acesso em: 15 dez. 2008.

NUCCI, J. C. Ecologia e Planejamento da Paisagem. In: Douglas Gomes dos Santos; João Carlos Nucci. (Org.). Paisagens Geográficas. Um tributo a Felisberto Cavalheiro. Campo Mourão: Editora da FECILCAM, 2009, p. 50-64. Disponível em: <http://www.fecilcam.br/editora/index.php?option=com_content\&task=blogcategory\&id=6\&Itemid=12>. Acesso em: 28 ab. 2010.

NUCCI, J. C. Aspectos teóricos do Planejamento da Paisagem. In: Planejamento da Paisagem como subsídio para a participação popular no desenvolvimento urbano. Estudo aplicado ao bairro de Santa Felicidade - Curitiba/PR. / Organização de João Carlos Nucci. Curitiba: LABS/DGEOG/UFPR, 2010, p. 14-25. Disponível em: <www.geografia.ufpr.br/laboratorios/labs/?pg=publicacoes-php>. Acesso em: 20 ago. 2008.

NUCCI, J. C.; CAVALHEIRO, F. Cobertura vegetal em áreas urbanas - conceito e método. Geousp, São Paulo, v. 6, n. 6, p. 29-36, 1999.

NUCCI, J. C. ; KRÖKER, R.; SCHMIDT, E. ; BUCCHERI FILHO, A. T. Mapeamento da qualidade ambiental urbana. In: Environmental Challenges of Urbanization, 2005, Brasília. International Congress on Environmental Planning and Management Environmental Challenges of Urbanization. Brasília : Catholic University of Brasilia, 2005. ISBN 85-905036-23.

NUCCI, J.C.; PRESOTTO, A. Planejamento dos espaços livres localizados em zonas urbanas. In: Douglas Gomes dos Santos; João Carlos Nucci. (Org.). Paisagens Geográficas. Um tributo a Felisberto Cavalheiro. Campo Mourão: Editora da FECILCAM, 2009, p. 78-102. Disponível em:

<http://www.fecilcam.br/editora/index.php?option=com_content\&task=blogcategory\&id=6\&Itemid=12>. Acesso em: 20 mai. 2010.

NUCCI, J. C.; VALASKI, S. Freiräume gleich unbebaute Räume? Ein bedeutsames Konzept für urbane Landschaftsplanung in Brasilien. Stadt und Grün, v. 10, p. 47-53, 2009.

PARANAGUÁ - Prefeitura Municipal de Paranaguá. Plano Diretor de Desenvolvimento Integrado de Paranaguá

(PDDIP). 2007. Disponível em: <http://www.helts.com.br/paranagua/plano_diretor.php>. Acesso em: 10 dez. 2008.

PIVETTA, A., CARVALHO J. A. DE, DALBEM R., MOURA A. R. DE, NUCCI J. C. Sistema de classificação da cobertura do solo para fins de comparação entre cidades e bairros. In: XI Simpósio Brasileiro de Geografia Física Aplicada, Anais. 2005. Universidade de São Paulo, pp.381-392. http://www.geografia.ufpr.br/laboratorios/labs

PIVETTA, A. Sistema de classificação da cobertura do solo do bairro de Santa Felicidade, Curitiba-PR, para fins de comparação entre cidades e bairros. Monografia de Bacharelado em Geografia - Universidade Federal do Paraná, 2006.

SANTOS, A. V. Memória histórica da cidade de Paranaguá e seu município. 3. ed. Paranaguá: Câmara Municipal, 1952. v. 1.

SCHMIDT, E. Avaliação da qualidade ambiental urbana do bairro Santa Felicidade, Curitiba/PR. 115 f. Dissertação (Mestrado) - Setor de Ciências da Terra, Universidade Federal do Paraná, Curitiba. 2009. Disponível em: <http://dspace.c3sl.ufpr.br:8080/dspace/handle/1884/18536>. Acesso em: 23 nov. 2009.

SITTE, C. - A construção das cidades segundo seus princípios artísticos. São Paulo, Ed. Ática, 1992 (1ºd. De 1889), 239p.

SUKOPP, H.; WERNER, P. Naturaleza em las ciudades. Madrid: Ministério de Obras Públicas y Transportes (MOPT), 1991.

TOLEDO, F. S.; SANTOS, D.G. Espaços Livres de Construção. Rev. SBAU, Piracicaba, v.3, n.1, mar. 2008, p. 73-91. 
TONETTI, E. L. Potencialidades de adensamento populacional por verticalização das edificações e qualidade ambiental urbana no município de Paranaguá, Paraná, Brasil. 235f. Tese (Doutorado) - Setor de Ciências da Terra, Universidade Federal do Paraná, Curitiba. 2011. Disponível em: <http://200.17.203.155/index.php?codigo_sophia=285569>. Acesso em: 12 abr. 2011.

TRAMUJAS, A. Histórias de Paranaguá - dos pioneiros da Cotinga à porta do Mercosul no Brasil Meridional. Paranaguá: Prefeitura Municipal de Paranaguá, 1996. 180 p.

VALASKI, S.; NUCCI, J.C. Espaços livres do bairro Boqueirão - Curitiba/Pr. In: XIII Semana de Geografia e VIII Jornada Científica de Geografia, Anais. Universidade Estadual de Ponta Grossa, 2006, pp.97-101. 